the three determinants used are determinants at the various ages studied, a contradictory transformation should produce a greater "surprise" and hence greater decrement in sucking than a consonant transformation. Accordingly, number of sucks emitted by each infant during each presentation was transformed into a proportion of the number of sucks expected from the basal rate. The proportion elicited by the contradictory transformation of each determinant was compared with the proportion elicited by the consonant transformation, to yield a chi-square with $5 \mathrm{df}$ for the significance of the difference between consonant and contradictory transformations of each determinant. Each age was treated separately with adjustment of values for multiple comparisons. The significance of these chi-squares is shown in Fig. 2.

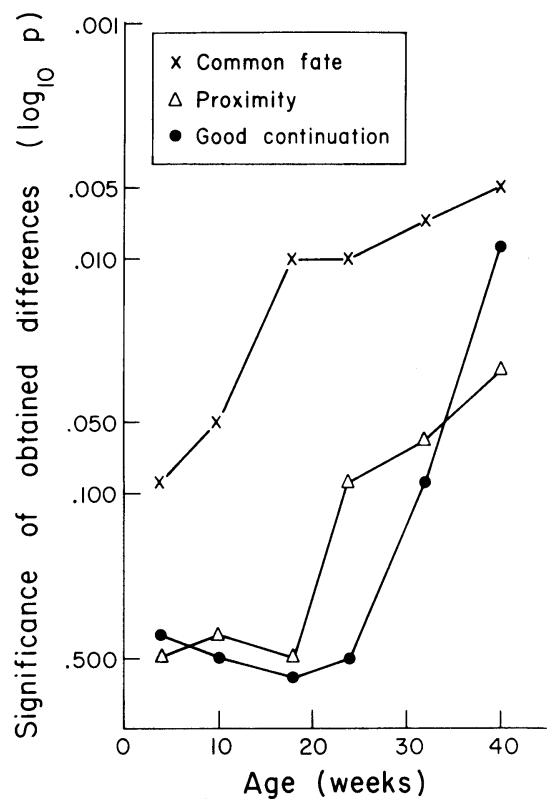

Fig. 2.

\section{Results and Diseussion}

As Fig. 2 shows, only common fate can be said to be a determinant of unity from the earliest ages studied. The others only gradually become effective. It may be objected that this experiment has measured the surprisal of various kinds of transformation and that these are unaffected by the determinants of unity which were introduced. This objection has little force for presentations (3) and (4), and (5) and (6), since both members of these pairs were subjected to the same kind of transformation. Only the consonance or nonconsonance of the transformation was different. However, for presentation (1) and (2), common fate, the objection has some force. To meet it, six more 10 week old infants were run through 12 presentations of (1) and (2) without the initial cueing $20 \mathrm{sec}$. The mean observed sucking proportions per presentation were (1) .12, (2) .26, a difference in the direction opposite to that obtained when common fate was cued.

The results obtained here support Brunswik's (1956) empiricist explanation of Gestalt laws. If common fate is an innate determinant of perceptual unity, as seems plausible, it might serve as the criterion for the others, the learning involved being a kind of correlation learning.

\section{References}

Berlyne, D. Conflict, arousal and curiosity. New York: McGrawHill, 1961.

Brunswik, E. Perception and the representative design of psychological experiments. Berkeley, 1956.

Bruner, J. S. On perceptual readiness. Psychol. Rev., 1957, 64, 123-152.

Hebb, D. O. The organization of behavior. New York: Wiley, 1949. Koffka, K. Principles of Gestalt psychology. New York: Harcourt Brace, 1935.

Note

1. This research was supported by N. I. M. H. research grant MF25-807. Preparation was supported in part by NSF G-5-192 to Harvard University through the Center for Cognitive Studies.

\title{
Erratum
}

Streufert, S., \& Driver, M. J. Conceptual structure, information load and perceptual complexity. Psychon. Sci., 1965, 3, 249-250. In next to the last line of column 2 on page 249 , the number of Ss should be 80 . 